\title{
Towards A Sustainable Fire-free Environment in Kebbi State: Causes and People's Behaviour in Fire Disasters
}

\author{
Alade E. Ilori ${ }^{1 *}$ and Rabiu A. Magaji ${ }^{1,2}$ \\ ${ }^{1}$ Centre for Disaster Risks Management and Development Studies, Ahmadu Bello University, Zaria, \\ Nigeria. \\ ${ }^{2}$ Department of Human Physiology, Ahmadu Bello University, Zaria, Nigeria.
}

\begin{abstract}
Authors' contributions
This work was carried out in collaboration between both authors. Author AEI conducted the literature search, designed the study, collect data, performed the statistical analysis and wrote the protocol and wrote the manuscript. Author RAM supervised the progress of the study. Both authors read and approved the final manuscript.

Article Information

DOI: $10.9734 /$ AJGR/2019/v2i430095

Editor(s):

(1) Dr. Hani Rezgallah Al-Hamed Al-Amoush, Associate Professor, Department of Earth and Environmental, Institute of Earth and Environmental, Al al-Bayt University, Jordan.

Reviewers:

(1) I. Yakubu, University of Mines and Technology, Ghana. (2) Ahmad Albattat, Management and Science University, Malaysia. Complete Peer review History: http://www.sdiarticle4.com/review-history/53708
\end{abstract}

Original Research Article

Received 28 October 2019

Accepted 04 January 2020

Published 13 January 2020

\begin{abstract}
Fire disaster is accident that occur most frequently with different causes. It requires strong intervention for a sustainable fire-free environment. This study assessed causes and people's behaviour in fire disasters towards a sustainable fire-free environment in Kebbi State, Nigeria. The study focused at identifying remote causes of fire disasters in Kebbi State, the people's behaviour in/to fire situations using the state capital (Birnin Kebbi) as well as equipment available in the state fire service head-office towards a fire-free environment. Descriptive research approach was used. A sample size of 204 respondents (30 market traders, 144 occupants and 30 fire service personnel) obtained through Cochran 1963 sample size formula were randomly selected. Questionnaire and observation were used to collect data which were analyzed through descriptive statistics (frequency tables and percentages) and results were presented in charts. Results revealed that electrical fault/wiring, political reasons, negligence among others are the causes of fire disaster in the area with electrical fault/wiring as the remote cause. The behaviour of people towards building a
\end{abstract}


sustainable fire-free environment shows people of the area do help one another in extinguishing fire whenever it strikes. Results also shows that lack of manpower and standard fire stations were the prominent challenges faced by the state fire service head-office in the state capital prompting incessant burning and resulting lives and property loss. Occupants of the area should always read and comply with safety guides of electrical appliances bought before use to avoid and prevent them from substandard gadgets that have ability of endangering their lives.

Keywords: Causes; sustainable environment; fire disaster; human behavior; Kebbi State.

\section{INTRODUCTION}

Fire outbreak is accident that occur most frequently with different causes. It requires strong intervention for a sustainable fire-free environment. According to Murali, and Vijayalakshmi [1] fire accident is an unplanned or unexpected event in the building environment. Henderson and Mackay [2] defined fire as the byproduct of a reaction of three different elements that is, the combustible material (fuel), air (oxygen) and ignition source (heat) in form of flame and light. The removal or insufficient of one of these elements to continue the chain reaction extinguish the fire [3]. Fire phenomenon is one of the most destructive forces causing extensive damage to natural environment, residential and commercial structures, and human settlements across the globe despite the technological advancement in fire safety $[4,5]$. The experience in the urban settlements are common with intense specifically in the residential buildings [6].

Incidents of fire in Nigeria continues to be on the increase every day as no day goes by without a report of fire at residential buildings and workplaces [7]. Oladokun et al. [8] remarked that frequencies of fire incidents across various cities of Nigeria have become a major concern for researchers and stakeholders in the country, due to varying degree of loss of lives and property [7, 9]. Damages from fire outbreaks in Nigeria particularly Birnin Kebbi the state capital of Kebbi State in recent times are quite staggering and alarming. For instance, between November and December 2015, Birnin Kebbi experienced 54 incidences of fire with an estimated property

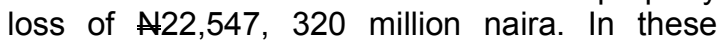
incidences, 9 lives were lost [10].

Despite the susceptibility of this area to various fire incidents and it maims on the residents, it is of great interest to note that the study area lack researches on potential causes of fire outbreaks and how people react (respond) in or to fire events for a sustainable fire-free environment of the area. It was on this note the study assessed the causes and people's behaviour in fire disasters using Birnin Kebbi as the spatial focus towards a sustainable fire-free environment in Kebbi State.

\section{LITERATURE REVIEW}

Several findings have shown that diverse variables are responsible for fire phenomenon in buildings and workplaces specifically. These variables are identified as causes of fire or fire hazards. Murali and Vijayalakshmi [1] were of the view that, causes or sources of fire and the extent of burning in a building are determined by the type of building, activities going on inside such building, behaviour of people in and outside the building, maintenance of the building, and fire preparedness and awareness of the users in such building $[11,12]$.

According to Tolofari [13] some fire outbreaks are caused by some individuals with malicious intent (arson) to show displeasure or create destruction. Instances of an estimated 282,600 arson caused fires reported to U.S fire departments between 2007 and 2011 resulted in 420 civilian deaths, 1,360 civilian injuries, and $\$ 1.3$ billion direct property damages [14]. In Ghana, fire outbreaks uprising were attributed to intense harmattan, overloading of electrical sockets and fuses, and installation of electrical gadgets in homes and workplaces by inexperienced electrician [15,16]. Another considerable factor is explosions from gasoline pipeline which has contributed significantly to burn injuries in the domestic settings in Nigeria [17].

Neglect and indiscipline on the part of government [15] was another greater influence of fire disaster in most places and cases. For instance, Yegor et al. [18] studied the impact of 2010 wildfires in Russia where more than 500,000 hectares of land were burned, more than 50 people died, and above 1,200 houses destroyed. The results revealed that the main causes of the fires were abnormal high temperatures, and failure of the government as 
acclaimed by more than half $(51 \%)$ of the respondents. Ignorance and smoking are another identified cause of fire disaster. According to Abu [19], majority (75\%) of fire outbreaks in Ghana are caused by smoking while those caused by ignorance accounts for $15 \%$ and $10 \%$ were from accidents. Simpson [20] in a paper titled "Fire protection and safety" in Ghana remarked that causes of fire in residential buildings, markets, workplaces and immediate humans' environments are but include naked flame from cooking stoves, gas and electric cookers, coal pots, as well as lighted mosquito coils, candles, and lanterns.

Despite the fact that causes of fire in and outside man's immediate environment are enormous with diverse effects, human behaviour in fire situation is important as it shows what people do and how they react. Investigating human behaviour is essential because in a certain fire situation everyone will not behave in the same way. According to Human Behaviour in Fire HBiF [21] human behaviour in fire is the study of reactions and actions taken by fire victims in a building, structure, and other areas. The study includes an understanding of people's beliefs, attitudes, motivations, awareness, decisions, and coping strategies alongside factors that influence them. Lending credence to this, Abubakar [22] observed that fate is not what drives men to their conditions or situations, but decisions and actions, or lack thereof.

The literature on human behaviour has identified series of factors liable for human decisions and actions in fire situations. Among these, Friberg and Hjelm [23] observed that, the level of education, age, past fire experience, gender, cultural believe of the victim(s) among others are key catalyst of every decisions and actions of man in fire situations. Kuligowski [24] opined that human action to/in a fire depends on the victim(s)'s awareness and interpretation of the situation. For example, due to low level of awareness and interpretation of fire situations in Dar-es-Salaam, Tanzania, respondents believed that it is the sole responsibility of fire and rescue teams and not theirs to prevent fire outbreaks within their immediate environment at the initial [25]. Lack of fire awareness may worsen the incidents than necessary.

Bryan [26] reviewed the behaviour of 580 people in fires mainly the dwelling areas. The study reported that the first action of people $(15 \%$ of the respondents) was to notify others about the incident and $10 \%$ affirmed search for the fire.
Nine percent $(9 \%)$ calls the fire department and $8 \%$ got dressed to extinguish the fire. Hopper et al. [27] conducted a survey on people who experienced fires in their homes using questionnaire. Their results indicated that people actually have a poor understanding of the different kinds of fire cues that exist. Mfinanga [25] as early discussed founded that, what people do in fire situation is they call fire fighter. In studies by Bryan [28] and Canter et al. [29] people shown that they will remain on their floor and fight the fire before the fire department arrives to save property and/or others from harm. Respondents in a study conducted by Averill et al. [30] agreed to seek information on the fire incident and help others to extinguish it.

\section{MATERIALS AND METHODS}

\subsection{Study Area}

Kebbi State is located in the northwestern zone of Nigeria. It was majorly carved from Sokoto State in the year 1991. The study further restricted the state coverage to Birnin Kebbi. The population of Birnin Kebbi the state capital was used for the fact that it is the administrative city of the state, thereby giving the researchers easy access to data. The researchers purposively used the working population of the city because the city experienced fire disasters than any other parts of the state. Metropolitan of Birnin Kebbi, Birnin Kebbi Local Government Area lies between latitudes $12^{\circ} 10^{\prime} 0^{\prime \prime} \mathrm{N}$ and $12^{\circ} 40^{\prime} 0^{\prime \prime} \mathrm{N}$ of the Equator and longitude $4^{\circ} 5^{\prime} 0^{\prime \prime} \mathrm{E}$ and $4^{\circ} 35^{\prime} 0^{\prime \prime} \mathrm{E}$ of the Greenwich Meridian [9,31]. The climate of the area is generally characterized by high temperatures ranging between March and May with means annual temperature varying between $38^{\circ} \mathrm{C}$ to $42^{\circ} \mathrm{C}$.

The area experiences harmattan wind between late November to early February with temperatures as low as $23^{\circ} \mathrm{C}$. Rainfall usually begins in late May, heavy fall were between July and October with mean annual rainfall varying between $500 \mathrm{~mm}$ to $800 \mathrm{~mm}$. Major activity of Birnin Kebbi indigenes is farming of crop varieties while some engaged in office works. Birnin Kebbi is dominated by Muslims and Christians as the religions practiced by both indigenes and non-indigenes. Naturally, the city is blessed with Neem (Azadirachta indica). It has physical and some social amenities like recreational centers. Major language spoken is Hausa/Fulani and other Nigeria and Niger languages as minor. 


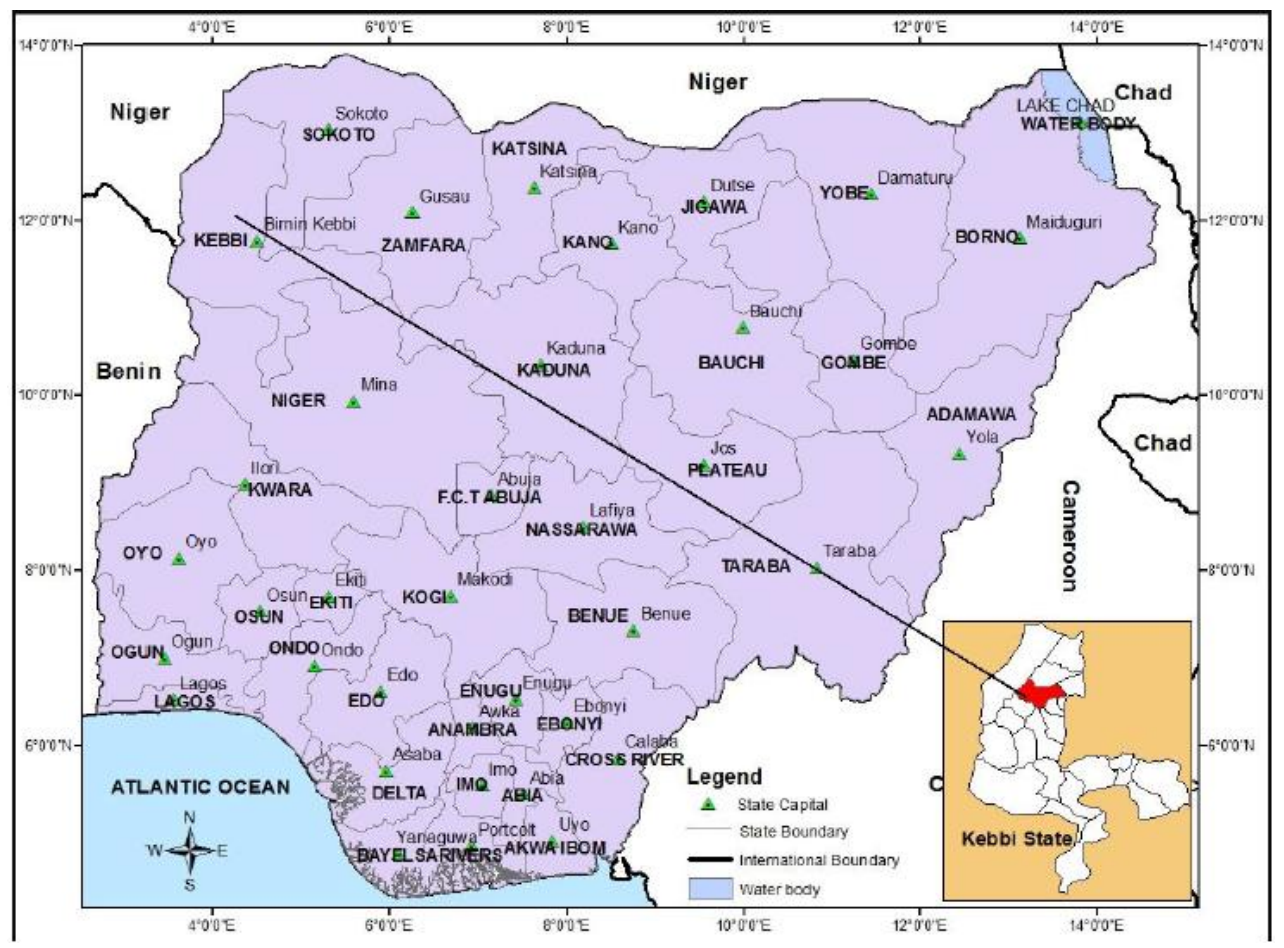

Fig. 1a. Nigeria showing location of Kebbi State Source: Kaoje et al. [31]

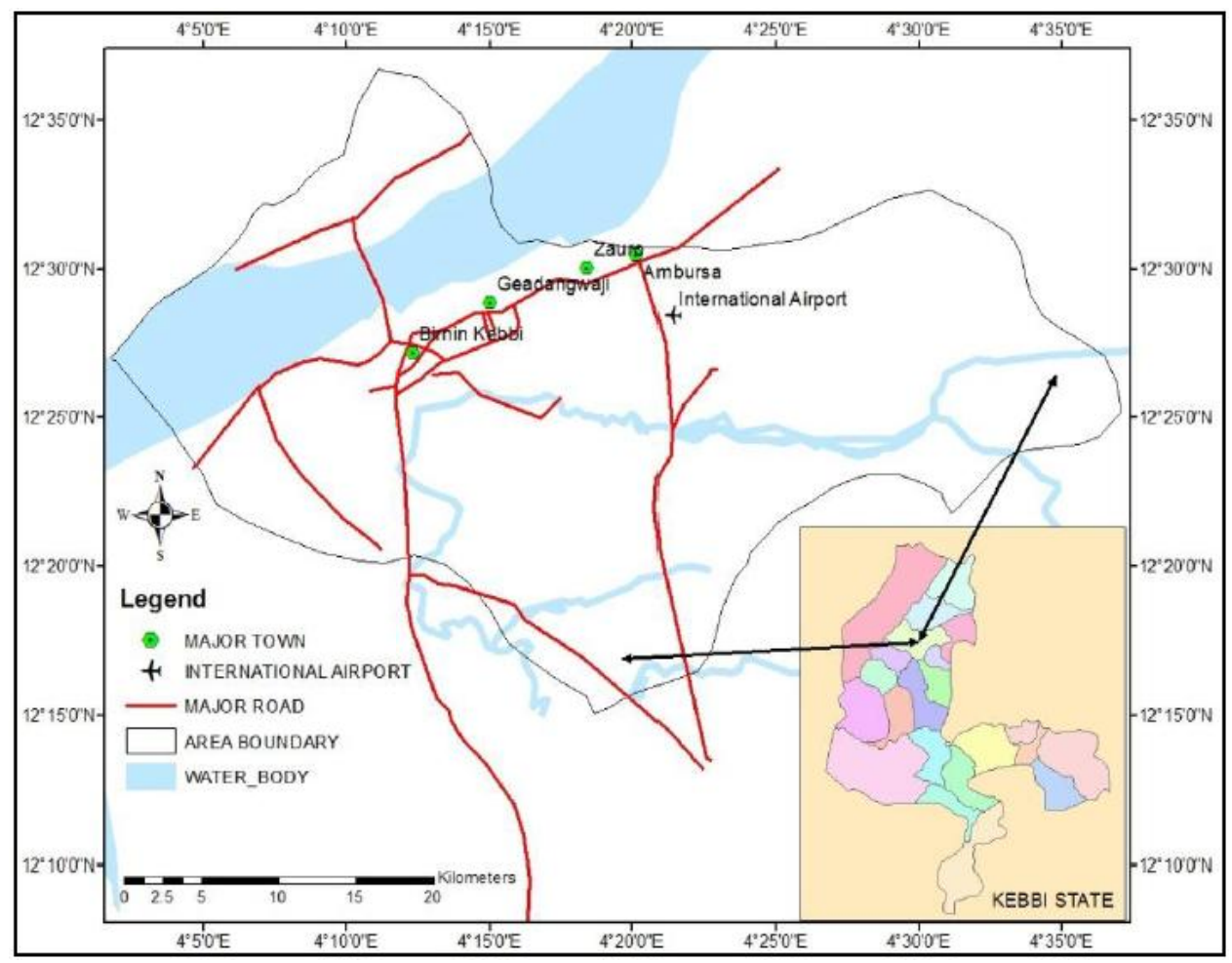

Fig. 1b. Birnin Kebbi Metropolis Source: Kaoje et al. [31] 
Descriptive research approach was used. Data were sourced through primary and secondary sources. The primary data on the causes of fire were obtained through structured and unstructured questionnaire from the residential/office buildings users, traders, and state fire service personnel. The behaviours (reactions) of people in fire situations in the area were sought from residential/office buildings users and traders. Information on the available facilities and equipment at the State Fire Service Head-office (SFSH) to contain fire incidents as well as challenges faced by the service to carry out required responsibility were sourced through questionnaire from SFSH personnel and unstructured interview with the SFSH deputy director.

Concurrently, facilities and equipment has the service to manage fire were observed. The secondary data includes review of related literature, and records of fire incidences between November, 2015 and October, 2016 in the capital city were sourced from the SFSH. This information served as a guide to the researchers on the occurrences of fire disaster in the area. Prevalence formula from Cochran [32] in equation 1 was adopted for the realization of the sample size used in this study, that is:

$$
\mathrm{N}=\frac{z^{2} p(1-p)}{e^{2}} \quad \text { Cochran [32] }
$$

Where $N$ is the sample size, $e$ is tolerance error (0.05), $p$ is the prevalence taken as $15.75 \%$ and $z$ is the level of significance that corresponds to $95 \%$ confidence level (that is, $z=1.96$ ). Thus, direct substitution of Equation (1) yields,

$N=\frac{1.96^{2}(0.1575)(0.1575)}{0.05^{2}}=204$ persons

Therefore, interested 204 persons sampled using convenient sampling method participated in the study. Hence, 134 residential/office buildings users, 30 market operators (traders) and 30 fire service personnel were administered questionnaire which contains demography data such as age, sex, marital status of the respondents. However, responses were statistically analyzed through descriptive statistics (frequencies and percentages) and presented in the form of table, pie and bar charts to take decision on various research objectives. Data collected were computed into 2013 version of Microsoft Excel application. However, using this package, any question with higher frequency and percentage is considered accepted and true while those with low were considered not accepted and subordinate.

\section{RESULTS AND DISCUSSION}

\subsection{Results}

Responses from questionnaire and the interview instruments on causes and people's behaviour in fire disaster in Birnin Kebbi are presented in this section. The demography characteristics of the respondents are indicated in Fig 2. As per gender, majority $(72.17 \%)$ of the respondents were male and their female counterpart were $27.84 \%$. On the respondents' age, $25.77 \%$ were between $21-26$ years, $20.62 \%$ were between 27 32 years, $25.77 \%$ of them were between $33-38$ years, $13.92 \%$ were between $39-44$ years, while $13.92 \%$ were 45 years and above. As at the time of this study, respondents that are yet to married were $43.3 \%$ while $52.58 \%$ has married, $1.55 \%$ were divorced and the widow respondents occupies $2.58 \%$. On educational attainment, majority $(42.78 \%)$ have OND/NCE certificate, $38.14 \%$ has HND/University degree, $7.73 \%$ had secondary school certificate, $8.76 \%$ was primary school leavers, $1.55 \%$ of the respondents had informal/Arabic, and only $1.03 \%$ did not attend any school.

Through the questionnaires instrument ${ }^{(1)_{\text {the }}}$ causes of fire disaster in Birnin Kebbi the state capital of Kebbi State were evaluated. The causes of fire disaster identified are shown in Fig 3. The results (refer Fig 3.) shows that, $57.73 \%$ of the respondents agreed that fire disasters in the area were due to electrical faults, $6.7 \%$ were due to carelessness, and $7.73 \%$ were due to negligence and ignorance. To $5.67 \%$ of the respondents, the phenomenon are caused by arson, $8.76 \%$ due to political reasons, $2.06 \%$ said the fires are caused from smoking and drugs, while $2.06 \%$ said they were as a result of gasoline and chemicals explosion. As further shown in Fig. 3, some respondents $(9.08 \%)$ did not respond to this question.

Results on the reactions (behaviour) of people during fire outbreak towards a sustainable fire free environment in Kebbi State using the state capital (Birnin Kebbi) are shown in Table 1. From Table 1, out of $164(100 \%)$ respondents whose questionnaire were suitable for analysis on reactions of people in fire tragedy, it was discovered that $50 \%$ declared positive behaviour of people by moving in mass to extinguish the 


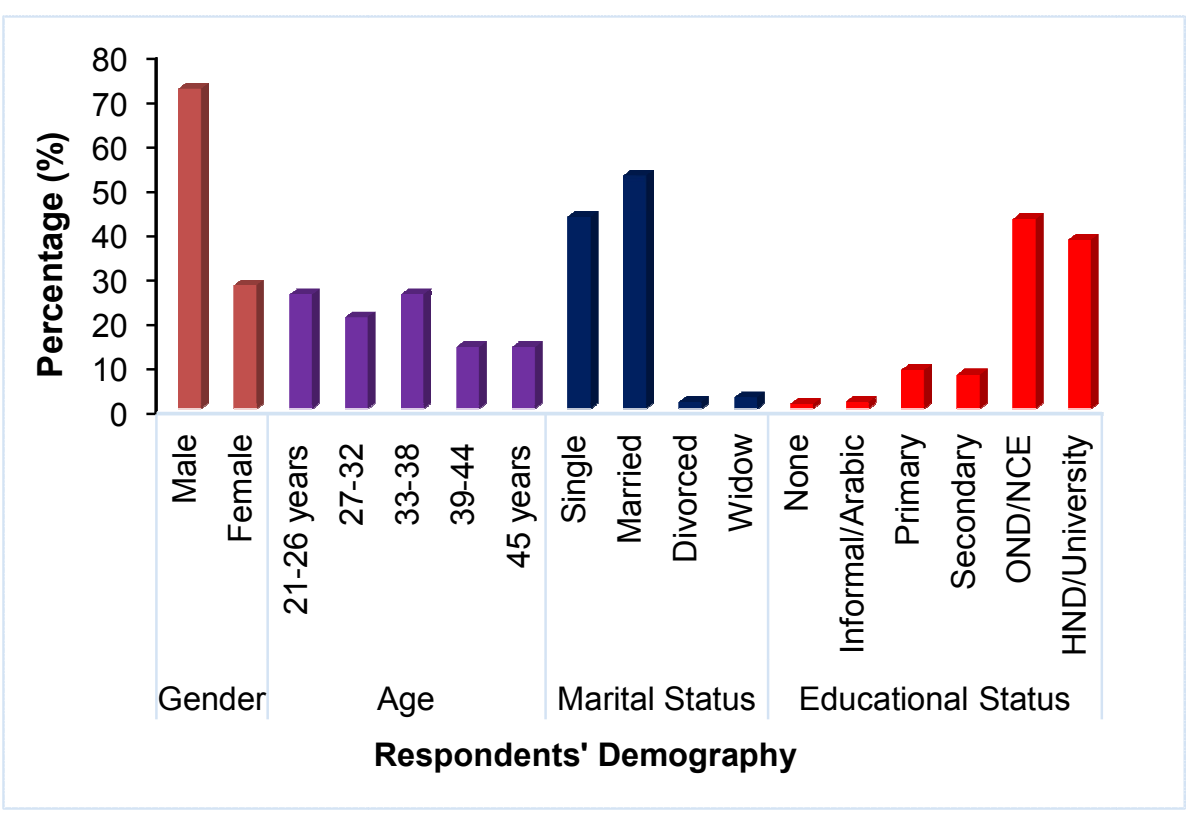

Fig. 2. Demography characteristics of the respondents

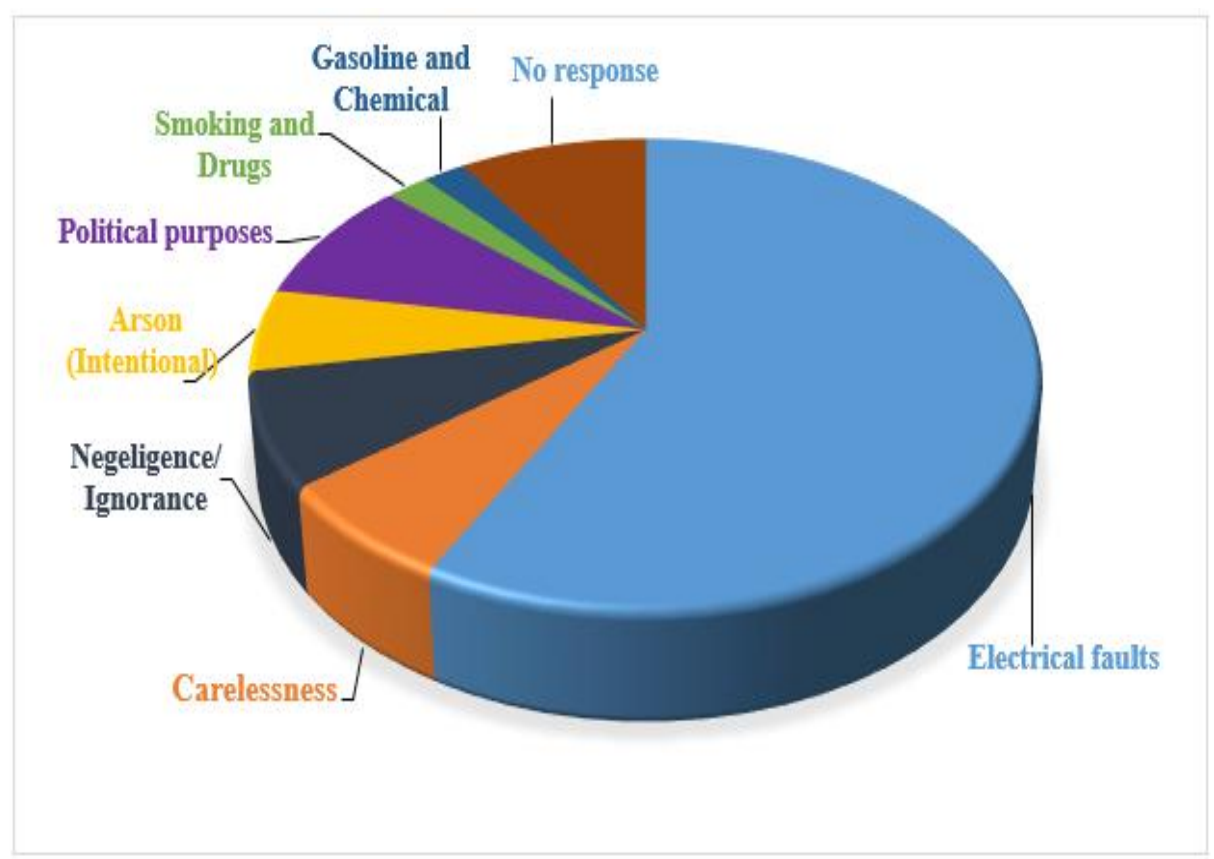

Fig. 3. Causes of Fire Outbreaks in Birnin Kebbi

incident before the arrival of fire personnel. As well before the situation goes out of hands. Some respondents $(32.32 \%)$ said people do call emergency line, $15 \%$ believe what people in such situation do cry, $9 \%$ opined that people only came round the scene to watch, while $5 \%$ failed to give their response as shown in Table 1.
Available firefighting facilities at the SFSH results are identified in Fig. 4. From the results, out of 30 $(100 \%)$ fire service personnel that responded to the questionnaire, majority of respondents $(26.7 \%$ and $20 \%)$ stated that dry chemical extinguishers and fire blanket respectively exist in the fire service office. Respondents (16.7\%) 
said carbon dioxide extinguishers exist, $10 \%$ each of the respondents affirmed that the service has halogen extinguishers, foam cylinders, and wet chemical. Only $6.7 \%$ agreed that sprinkler/hose reels do exist in the head-office. When asked whether any other fire equipment exists at the head-office, none of the respondents stated the existence of any other. The result also shown that only $23.3 \%$ out of $100 \%$ of the respondents declared enough equipment in the service station while $76.7 \%$ declared inadequate equipment when asked.

Apart from questions on the available firefighting facilities at the fire service head-office, the personnel were also asked to elucidate challenges facing the service to contain fire. The results to these are presented in Fig. 5. Looking at Fig. 5 it is evident that, $26.7 \%$ of the respondents stated Lack of manpower/staff, $13.3 \%$ said lack of equipment and $6.7 \%$ of the respondents lamented that many of the incidents happened at odd time. Poor communication skill from the community accounted for $6.6 \%$ while congestion of some areas like the market $(16.7 \%)$. Poor road network in areas like the market was view of $10 \%$ of the respondents, and $20 \%$ stated that no standard station are the main challenges of the station for effective service delivery.

\subsection{Discussion}

From the results shown in Fig. 2, the modal age of the respondents were $21-26$ years $(25.77 \%)$ and $33-38$ years with $25.77 \%$. From the results on education attainment, it was achieved that majority $(80.92 \%)$ of the respondents were OND/NCE holders. These two characteristics (age and education attained) implies that the respondents are adult and capable to answer the questions. Most $(52.58 \%)$ of the respondents are married. As per marital status shown in Fig. 2, the $52.58 \%$ married upheld the norms and faith practiced in the northern parts of Nigeria where according to the Islamic faith a grown up person that may be considered an adult (male or female) must be with his or her own spouse.

Table 1. Response on behaviour of people in fire disaster

\begin{tabular}{lll}
\hline Behaviour & Frequency & Percentage (\%) \\
\hline Crying & 15 & 9.15 \\
Call emergency line & 53 & 32.32 \\
Call neighbours for help/Moving in mass to extinguish fire & 82 & 50 \\
People came to the scene point to watch only & 9 & 5.49 \\
No response & 5 & 3.05 \\
\hline Total & $\mathbf{1 6 4}$ & $\mathbf{1 0 0}$ \\
\hline
\end{tabular}

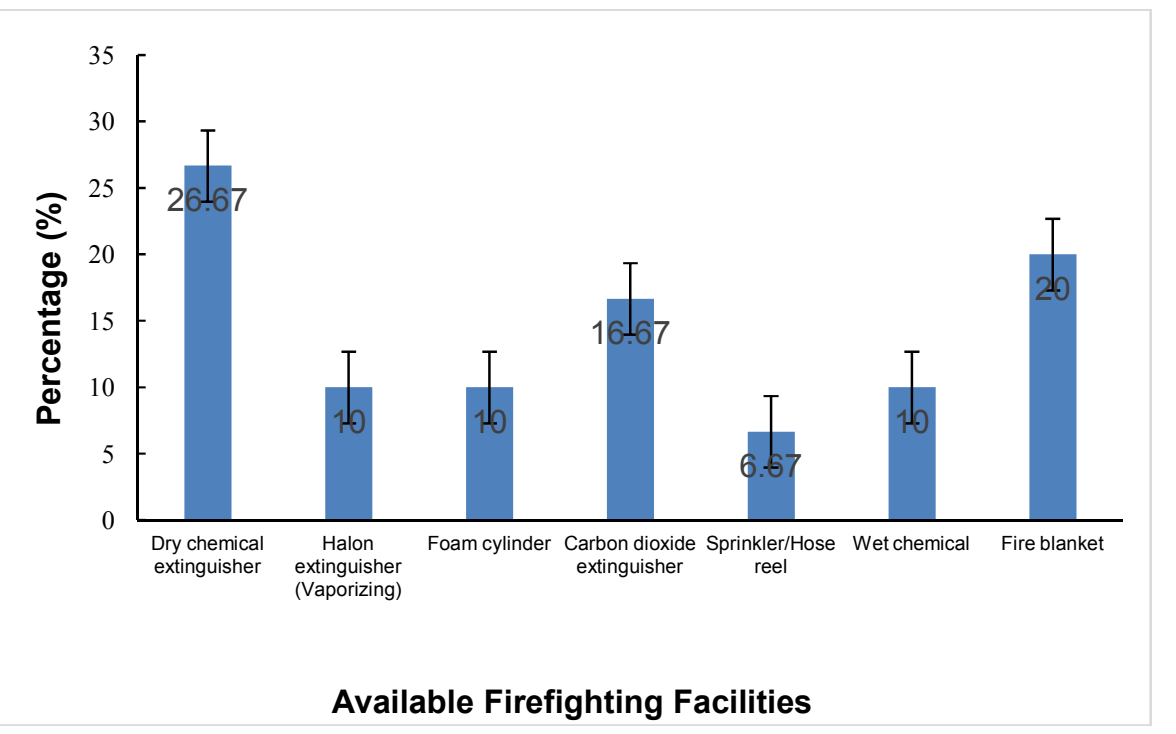

Fig. 4. Facilities available at the state fire service head-office to fight fire disaster 


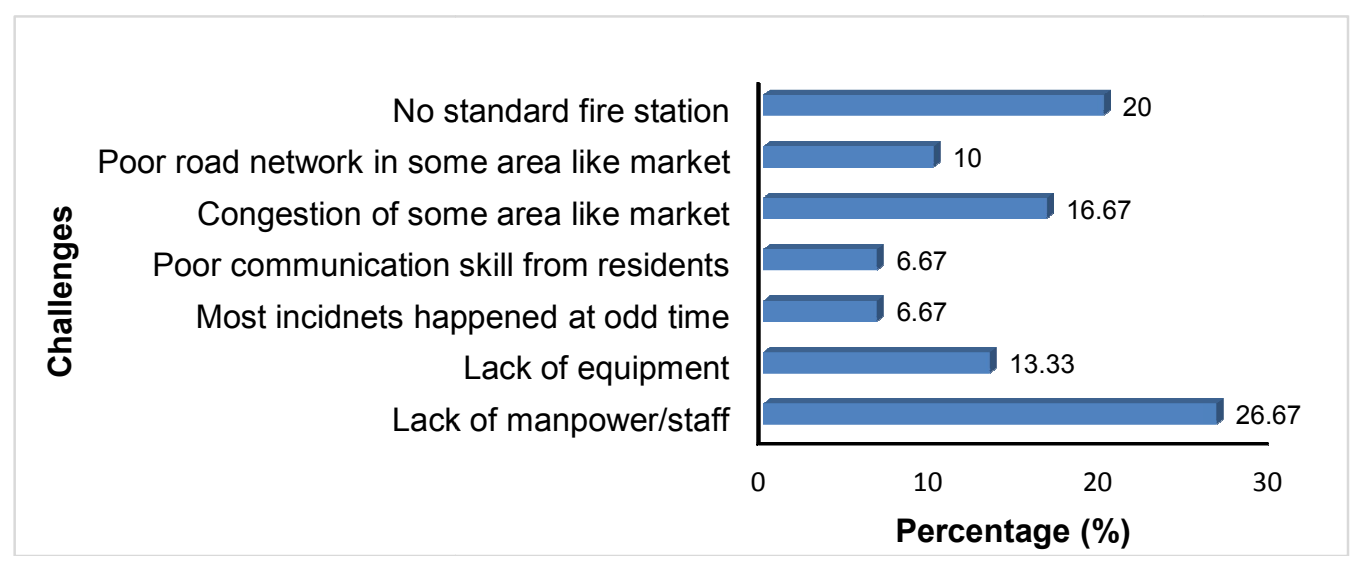

Fig. 5. Challenges faced by the state fire service head-office

Similar to marital status was the gender where majority $(72.17 \%)$ of the respondents were male (i.e. the traders, residential building occupants and the fire service personnel). Based on the culture and believes, it is an obligatory for men to cater for their family's daily up-keeping. More so, according to the norms of northern parts of Nigeria especially a state or community dominated by Muslim, a male visitor is not allowed to gain access to peoples' house anyhow hence, these gave males more opportunity to be ably represented than their female counterparts as shown in Fig. 2.

Based on the responses presented in Fig. 3 from the three categories of respondents and researchers observation, it was revealed that the causes of fire disaster includes electrical faults, use of gasoline (such as kerosene, petrol etc.) and chemical. Others are; smoking and drugs, arson, political purposes, carelessness, negligence and ignorance on the part of government and residents respectively. Findings in this study agreed with findings of Yegor et al. [18] in Tanzania and Aidoo [33] in Ghana that attributed the causes of fire incidence to the negligence on the part of government.

Among the causes discovered in this study, it was further revealed that electrical fault/wiring with agreement among $57.73 \%$ of the respondents is the prominent cause of fire outbreak in Birnin Kebbi as shown in Fig. 3. Electrical faults can be linked to different reasons such as high voltage which mostly experienced during the hammatan period in the area, noncompliance with electrical guides, overheating of electric wires, sparks, and so on. Supporting the finding was the result of Anaglatey [15] who inferred overloading of electrical appliance on the same fuse, improper electrical installation in homes and workplace among others to the cause of fire outbreak in Ghana.

However, in every emergency situation such as fire disaster, the behaviour of people is always different in such event. On the behaviour of people in fire tragedy in the study area, people do move in mass to help victims to extinguish fire so as to reduce and curtail the spread whereas some engaged in calling emergency line of the fire service head-office. This was ascertained from $50 \%$ and $32.32 \%$ of the respondents respectively from Table 1 . Helping others in an awkward situation like fire is necessary because it reduces the strength of the fire combustion from getting out of hands. Although, from the results in Table 1, 5.49\% of the respondents acclaimed that some people feels less concerned about fire incident as they neither help to extinguish the fire nor assist in calling help line but instead they came around the scene only to watch. Such character displayed could be influenced by interpretation of the situation [24] and other factors as described by Friberg and Hjelm [23].

Regarding available firefighting equipment in the fire service head office as well as the challenges faced by the service to discharge her responsibilities, it was indicated that the major available firefighting facilities in the service head office were dry chemical extinguisher $(26.67 \%)$, fire blanket $(20 \%)$, and carbon dioxide extinguisher $(16.67 \%)$ as shown in Fig. 4. From the findings firefighting gadgets/equipment is not enough in the station because when asked only $23.3 \%$ of the respondents declared enough equipment in the service station while $76.7 \%$ 
declared inadequate equipment. Firefighting facilities are used by trained professional/persons to fight fires incidents from escalating and to reduce the spread. The lack of these facilities can jeopardized the safety of lives, property and as well increase the loss. For instance, between November, 2015 and December, 2016 the state capital (Birnin Kebbi)

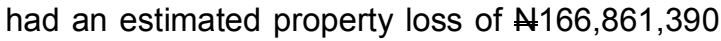
which was even above the estimated property saved of $\mathrm{A} 152,312,821$ million naira [10].

Facilities/gadgets like radio call, and mega phone which can be used to address the public during awareness and stimulations were not possessed by the service and this could lead to poor outreach. Meanwhile, the internet that will help in latest firefighting gadgets were also not available and this has brought about the outdated equipment as well as lack of necessary information about new and latest equipment. Consequently, lack of firefighting facilities at the disposal of firemen will create serious difficulty in fighting a fire especially at the early stage and wherefore, the incident may escalate and destroy lives and properties. Looking at the results, it can be said that the findings agreed with the view of Ahmed [34] who asserted that, in spite of the magnitude of fire incidents in the north-west of Nigeria, the various fire service stations remain incapacitated due to long time neglect by government.

On the other hand, problems faced by the service to discharge it responsibilities includes congestion in area like market, lack of staff (manpower) and standard fire station to manage fire outbreak (refer Fig. 5). Supporting these, the deputy director of SFSH, Birnin Kebbi during the interview lamented that "We don't have manpower, I think the last time government recruit firemen last was during Governor Aleiro administration in 2006. From look of things, our vans are serviceable, and the available facilities to fight fire are inadequate". These challenges faced by the fire service department have led to poor performance of the state head office as specifically pointed by the market operators hence increasing the susceptibility of the people of the area to fire dangers. Meanwhile, for a sustainable fire-free environment these challenges have to be curbed to reduce resulting effects of fires on socio-economic status of people in the area as well as unnecessary expenses on compensation of fire victims, rehabilitation of destroyed property among others by the state government.

\section{CONCLUSION}

Based on results of study, it was concluded that:

i. Fires disaster occurrences in Birnin Kebbi are caused as a result of electrical fault, smoking and drugs, political purposes, negligence and ignorance, gasoline and chemicals, carelessness, and arson.

ii. Electrical fault is the prominent cause of many fires in the area among the causes identified.

iii. People of the area do turn out in mass and always respond to help victim(s) of fire outbreak so as to reduce the combustion and the spread whenever there is fire in the area.

iv. Kebbi State Fire Service Head-office is illequipped with latest firefighting facilities to combat fire as only dry chemical extinguisher, fire blankets, and carbon dioxide extinguishers were the commonest available firefighting equipment in the station.

v. Major challenges of the service to contain fire were lack of staff (manpower), lack of standard fire station, and congestion especially at the central market.

\section{RECOMMENDATION}

Based on the outcome of the study, the following recommendations are made:

i. Occupants of the area should always read and comply with safety guides of electrical appliances bought before use to avoid and prevent them from substandard gadgets that have ability of endangering their lives. Hence, people with "I don't care attitude" in the area should refrain from such behaviour.

ii. State government through fire service head office should invest on both radio and television jingles on the needs for fire safety and fire-fighting equipment acquirement.

iii. State government should recruit more hands to boost service delivery of the fire service personnel in the area as the service is highly challenged with under staffing.

iv. In the case of the market, state government and individuals investors should ensure provision of proper and adequate fire-fighting facilities to prevent constant fire outbreak. 
v. Fire service should be an independent entity and not a department under ministry of works.

vi. There should be a study on the effects of 2016 Birin Kebbi central market fire experience on the traders investment since this study did not open or treat this quota.

\section{ACKNOWLEDGEMENT}

The researchers acknowledge the participants from Birnin Kebbi, Kebbi Sate for the information provided and the success of this research.

\section{COMPETING INTERESTS}

Authors have declared that no competing interests exist.

\section{REFERENCES}

1. Murali PLG, Vijayalakshmi MM. Fire accidents in buildings - Case studies. International Journal of Engineering Trends and Technology (IJETT). 2014; 11(4):178.

[ISSN:2231-5381]

Available:http://www.ijettjournal.org

2. Henderson J, MacKay S. Retail availability of fire-starting materials and their misuse by children and adolescents. Fire Safety Journal. 2009;44(1):131-134.

3. Furness A, Muckett M. Introduction to fire safety management. Armsterdam: Elsevier; 2007.

4. Blank ME. The role of fire prevention in protecting facilities; 2004.

Available:http://magazine.sfpe.org/fireprote ction-design/role-fire-prevention-protectingfacilities

5. Ramachandran G, Charters D. Quantitative risk assessment in fire safety; New York: Spon Press; 2011.

6. Yohannes K, Jacob K, Huba N. Assessing Urban Fire Risk in the Central Business District of Dar-es-Salaam, Tanzania. JAMBA: Journal of Disaster Risk Studies. 2010;3(1).

7. Ilori AE, Sawa BA, Gobir AA. Application of cause-and-effect-analysis for evaluating causes of fire disasters in public and private secondary schools in llorin Metropolis, Nigeria. Archives of Current Research International. 2019;19(2):1-11.

8. Oladokun VO, Kolawole A, Emmanuel CG. Risk analysis models of fire accidents in
Nigeria commercial complexes: A fuzzy logic approach. Proceedings of NIIE Conference. Benin City, Nigeria; 2012.

9. Ilori AE. Assessment of the causes and the people's behaviour in fire disaster in Birnin Kebbi, Kebbi State, Nigeria. (Unpublished Master's Project, School of Postgraduate Studies, Ahmadu Bello University, Zaria). 2017;1-135.

10. State Fire Service Head-office SFSH. Fire disaster incidents in Birnin Kebbi, Kebbi State, Nigeria. November 2015 to Octerber, 2016 Report. Birnin Kebbi; 2016.

11. Usman S, Morton J, Koko IS, Aminu A, Makai AA, Adamu A. Climate Change and Soil Degradation Impact: Farmers' viewpoints in Kebbi State Nigeria. International Journal of Current Research and Review. 2013;5(5):63.

12. Omoleke SA, Alabi O, Shuaib F, Braka F, Tegegne SG, Umeh GC, Mohammed K. Environmental, economic and sociocultural risk factors of recurrent seasonal epidemics of cerebrospinal meningitis in Kebbi State, northwestern Nigeria: A qualitative approach. BMC Public Health. 2018;18(4):1318.

13. Tolofari M. Fire outbreak in Nigeria. The Tidenews. (Online). December. 2010;24. Available:http://www.thetidenewsonline.co m/2010/12/24/fire-outbreaks-in-nigeria/

14. Campbell R. Intentional fires. National Fire Prevention Association (NFPA): News \& Research; 2014.

15. Anaglatey PB. Accra continues to record fire outbreaks. The Chronicle. 2013;30.

16. Hassan GA. Drought, drought mitigation in Yobe State, Nigeria (Doctoral dissertation); 2018.

17. Fadeyibi IO, Omosebi DT, Jewo PI, Ademiluyi SA. Mass burns disaster in Abule-Egba, Lagos, Nigeria from a petroleum pipeline explosion fire. Ann Burns Fire Disasters. 2009;22:97-103.

18. Yegor L, Anton S, Irina S, Boris S. Trial by fire: A natural disaster's impact on support for authorities in rural Russia. Basic Research Program Working Papers. National Research University Higher School of Economics; 2012.

19. Abu J. Smoking is number one cause of fire outbreak in Ghana. Ghana News Agency. 2013;18.

20. Simpson DE. Fire protection and safety. A Presentation of Ghana National Fire Service (GNFS). Ashanti Regional office at a Symposium of Building Technology 
Students Society (BTSS) week celebration, Kwame Nkrumah University of Science and Technology (KNUST), Kumasi. 2010; 24-27.

21. Human Behaviour in Fire HBiF. Definition of human behaviour in fire. The 6th Human Behaviour in Fire Symposium. Bromley, UK; 2015.

22. Abubakar S. Market fires: Not sabotage, but greed and stupidity (Online). Daily Trust. 2016;5.

Available:https://www.dailytrust.com.ng/ma rket-fires-not-sabotage-but-greed-andstupidity.html

23. Friberg M, Hjelm M. Mass evacuation human behaviour and crowd dynamicswhat do we know? Department of Fire Safety Engineering Lund University, Lund; Sweden; 2014.

24. Kuligowski ED. The Process of Human Behavior in Fires, NIST Technical Note 1632, Department of Commerce, USA; 2009.

25. Mfinanga DA. Parking generation by facilities in the CBD of Dar-es-Salaam City. The Journal of Building and Land Development. 2007;14(2):83-99

26. Bryan JL. An examination and analysis of the dynamics of the human behaviour in the Westchase Hilton Hotel Fire. Mass: NFPA (Mimeo); 1983.

27. Hopper L, Taylor R, Pepperdine S, The MFB's Human Behaviour Research Project, London: Interscience Communications Ltd.; 2002.

28. Bryan JL. Smoke as a determinant of human behavior in fire situations (Project People) (Rep. No. NBS-GCR-77-94).
Washington, DC: National Bureau of Standards; 1977.

29. Canter D, Breaux J, Sime J. Domestic, Multiple Occupancy and Hospital Fires. In David C. Fires and Human Behaviour (Ed.), New York, NY: John Wiley \& Sons. 1980;117-136.

30. Averill JD, Mileti DS, Peacock RD, Kuligowski ED, Groner N, Proulx G, Reneke PA, Nelson HE. Federal building and fire safety investigation of the world trade centre disaster: Occupant behaviour, egress, and emergency communications. (Report). NCSTAR. In Gaithersburg, MD: National Institute of Standards and Technology. 2005:1-7.

Available:http://wtc.nist.gov/NISTNCSTAR 1-7.pdf

31. Kaoje IU, Dankani IM, Ishiaku I. Site Suitability Analysis for Municipal Solid Waste Disposal in Birnin Kebbi, Nigeria. IOSR Journal of Humanities and Social Science (IOSR-JHSS). 2016;21(7):01-10, Ver. 3.

DOI:10.9790/0837-2107030110

32. Cochran WG. Sampling Techniques, (2nd Ed.). New York: John Wiley and Sons, Inc. 1963;75.

33. Aidoo T. Indiscipline by authorities are the main causes of fire outbreaks in our markets. 2013.

Available:http://www.myradiogoldlive.com/i ndex.php/general-news/2771-indisciplineby-authoritiesare-the-main-causes-of-firesin-our-markets-tony-aidoo

34. Ahmed M. Fire outbreak: Fire service stations in north-west ill equipped, under staffed. NAN Survey. 2016;15.

Available: http://www.dailynews.co.tz/

(c) 2019 Ilori and Magaji; This is an Open Access article distributed under the terms of the Creative Commons Attribution License (http://creativecommons.org/licenses/by/4.0), which permits unrestricted use, distribution, and reproduction in any medium, provided the original work is properly cited.

Peer-review history:

The peer review history for this paper can be accessed here: http://www.sdiarticle4.com/review-history/53708 